\title{
Laparoscopic Nissen fundoplication combined with posterior gastropexy in the surgical treatment of gastroesophageal reflux disease (GERD)
}

\author{
Christopher S. Davis • P. M. Fisichella
}

Received: 18 May 2010/Accepted: 1 July 2010/Published online: 7 December 2010

(C) Springer Science+Business Media, LLC 2011

We read with interest the work by Tsimogiannis et al. [1], whose prospective randomized trial supported the use of a posterior gastropexy as a component to laparoscopic Nissen fundoplication. The level of evidence they reported is crucial to standardizing the technique of laparoscopic antireflux surgery. To date, evidence has largely been either observational or retrospective in nature despite the fact that antireflux surgery has been described for half a century.

The inclusion of a gastropexy to prevent herniation of the fundoplication into the chest can be attributed to Rudolph Nissen [2] in 1961. Shortly thereafter, in the late 1960s, Lucius Hill [3] pioneered the repair that bears his name by demonstrating a successful posterior gastropexy that entailed anchoring the gastroesophageal junction to the median arcuate ligament. By 1977, after using this approach for 559 patients undergoing surgery for hiatal hernia, Dr. Hill [4]reported only $5(0.89 \%)$ recurrences with $95 \%$ follow-up assessment.

We applaud the authors for finally providing level 1 evidence that a posterior gastropexy has a positive impact on the results of the operation without worsening dysphagia. We in fact use a posterior gastropexy routinely during our laparoscopic Nissen fundoplications, even after lung transplantation [5]. Furthermore, in addition to the gastropexy described by Tsimogiannis et al. [1], we routinely place two stitches, one on each side of the fundoplication, to pexy the fundoplication and the esophagus to the diaphragm. These "apical" stitches incorporate the top of the fundoplication, the esophagus, and the uppermost portion of the crus, and at the same time pexy the fundoplication so as to avoid telescoping of the esophagus through the repair.

Disclosures Christopher S. Davis and P. M. Fisichella have no conflicts of interest or financial ties to disclose.

\section{References}

1. Tsimogiannis KE, Pappas-Gogos GK, Benetatos N, Tsironis D, Farantos C, Tsimoyiannis EC (2010) Laparoscopic Nissen fundoplication combined with posterior gastropexy in surgical treatment of GERD. Surg Endosc 24:1303-1309

2. Nissen R (1961) Gastropexy and "fundoplication" in surgical treatment of hiatal hernia. Am J Dig Dis 6:954-961

3. Hill LD (1967) An effective operation for hiatal hernia: an eightyear appraisal. Ann Surg 166:681-692

4. Hill LD (1977) Progress in the surgical management of hiatal hernia. World J Surg 1:425-436

5. Davis CS, Jellish WS, Fisichella PM (2010) Laparoscopic fundoplication with or without pyloroplasty in patients with gastroesophageal reflux disease after lung transplantation: how I do it. J Gastrointest Surg. doi: 10.1007/s11605-010-1233-1238
C. S. Davis · P. M. Fisichella ( ()

Department of Surgery, Loyola University Medical Center, Stritch School of Medicine, 2160 South First Avenue, Room 3226, Maywood, IL 60153, USA

e-mail: chdavis@lumc.edu 